\title{
IMPLEMENTATION OF THE SIX SIGMA METHODOLOGY IN INCREASING THE CAPABILITY OF PROCESSES IN THE COMPANY OF THE FURNITURE INDUSTRY OF THE SLOVAK REPUBLIC
}

\author{
L'ubica SIMANOVA, Pavol GEJDOŠ \\ Technical University in Zvolen
}

\begin{abstract}
:
The aim of the article is to present the results of a case study focused on the implementation of the Six Sigma methodology in order to improve the quality and increase the efficiency of furniture production processes. Positive results of implementation after the implementation of corrective measures were achieved in the values of process capability coefficients, reduction of nonconformities and subsequent reduction of DPMO, increase of the values of the level of efficiency and sigma of the critical process. In the processing of the results, classical methods of research work were used such as analysis, synthesis, comparison, descriptive statistics, coefficients $C_{p}$ a $C_{p k}$, DPMO, level of efficienty and sigma, and also graphic methods.
\end{abstract}

Key words: process, capability, Six Sigma, process improving, quality, performance

\section{INTRODUCTION}

A company that wants to be a leader in its industry must use new modern concepts and approaches. Most enterprises in Slovakia are engaged in production activities, while the production process itself consists of a large number of complicated operations, which changes the variability and capability of processes. The furniture industry in Slovakia consists mainly of micro enterprises, small and medium-sized enterprises. The aim of the work is to present the results of a case study focused on the implementation of the Six Sigma methodology in increasing the capability of processes in a particular enterprise of the furniture industry in the Slovak Republic. The uniform criteria for comparison were the capability coefficients $C_{p}$ and $C_{p k}$, as well as the DPMO values, the efficiency and sigma levels, which were influenced by the different characteristics of the processes, but at the same time, provided a uniform platform for comparison.

\section{MATERIAL AND METHODS}

The authors agree that Six Sigma is a methodology focused on the improvement of manufacturing processes, where product quality is the response variable for all activities. The aim of Six Sigma is to produce no more than 3.4 defects per million opportunities, making it an appealing proposition for production managers. This is perhaps the most important definition of Six Sigma as a methodology, since it implies that processes must be appropriately standardized $[2,4,11,17,19]$.
Six Sigma is the structured process improvement method. It is providing the user with a more detailed outline of Deming's PDCA by guiding the initiative through a fivestage cycle of define, measure, analyse, improve, control. There are specific tools and techniques for each phase. The key to success of Six Sigma is training, senior management interest and active role in project selection [14, 16]. Authors see the success of Six Sigma implementation in the support of top management, in the implementation of quality programs and in the knowledge that influences competitive advantage $[1,20,25]$. Authors point to shortcomings related to an organization's ability to apply Six Sigma [17]. The lack of Six Sigma capabilities in the organization is therefore the result of a lack of support from top management and insufficient resources (for change management), quality programs, as well as the maturity of the organization and knowledge [21]. A major factor influencing the success of Six Sigma implementation is the failure to manage cultural change and implement any quality philosophy [12].

According to a number of researchers the process capability index $\mathrm{PCl}$ can be used a 6-sigma evaluation tool and successfully applied in various industries. $\mathrm{PCl}$ measure the quality and performance of processes $[5,8,23]$. In determining the critical process, the process capability measurements were performed according to the following methods: 
- Measurement plan according [7, 13]: five-phase measurement plan methodology.

- $C_{p}$ and $C_{p k}$ capability indices: an assessment of the process's critical capability in terms of compliance with set or expected limits and average value $[15,18]$.

Process capability refers to the assessment of how well a process meets specifications or the ability of a process to produce parts that comply with technical specifications. The authors consider the $C_{p}$ and $C_{p k}$ indices to be the most used basic indicators of competence in the manufacturing industry $[3,8,16,24]$.

Relevant data for the calculation of critical indicators of furniture production processes were obtained from the database of the surveyed enterprise and by own measurement of process characteristics.

A critical process and a specific problem in the process were identified by the defect analysis in the process. Defects were divided into material and technological. There were used calculations of the DPMO value, the process efficiency as total output revenue and a level of Six Sigma. DPMO (Defects per Million Opportunities) denominates the number of defects that occur per one million of opportunities at the development or manufacturing of a product [9].

The obtained data were processed and exported from Excel to modules of Descriptive Statistics and Industrial Statistics \& Sigma - Process Analysis STATISTICA 12 CZ.

\section{RESULTS AND DISCUSSION}

The aim of the paper is to present the results of the implementation of the Six Sigma methodology for improving the quality and increasing the efficiency of furniture production processes. Its implementation according to the DMAIC steps was focused on determining and comparing the suitability of furniture production processes through $C_{p}$ and $C_{p k}$ capability indices, as well as DPMO results, efficiency and sigma levels of the critical side banding process. The implementation was carried out in a specific enterprise of the furniture industry. Part of the presented results is also a comparison of the percentage of disagreements in the critical process before and after the implementation of corrective measures to eliminate disagreements and the benefits of implementing the Six Sigma methodology within a three-month evaluation period. To ensure the quality and performance of processes in the furniture enterprise, according to the DMAIC steps were used.

The stage Define:

Based on the analysis of non-conforming parts in the furniture production process and subsequent DPMO calculations, efficiency levels and sigma levels, we came to the conclusion that the critical process is the process of bonding the side surfaces of furniture parts. A comparison of DPMO values, efficiency levels and sigma of furniture production processes is given in Table 1 .
Table 1

Comparison of DPMO, efficiency and sigma levels of furniture production processes

\begin{tabular}{lccc}
\hline \multicolumn{1}{c}{ State } & DPMO & $\begin{array}{c}\text { Level of efficiency } \\
\text { \% }\end{array}$ & $\begin{array}{c}\text { Level } \\
\text { of Sigma }\end{array}$ \\
\hline Formatting & 19512 & 98.05 & 3.53 \\
Pressing & 13308 & 97.70 & 3.73 \\
Bonding of side & 139389 & $\mathbf{8 6 . 0 6}$ & $\mathbf{2 . 5 8}$ \\
surfaces & 16260 & 98.37 & 3.64 \\
Grinding & 13930 & 98.61 & 3.70 \\
Drilling holes & 17756 & 98.27 & 3.61 \\
Mounting & & & \\
\hline
\end{tabular}

In the definition phase, an analysis of non-conforming parts in the critical process of bonding the side surfaces for the observed period of three months was also performed, which is recorded in Fig. 1.

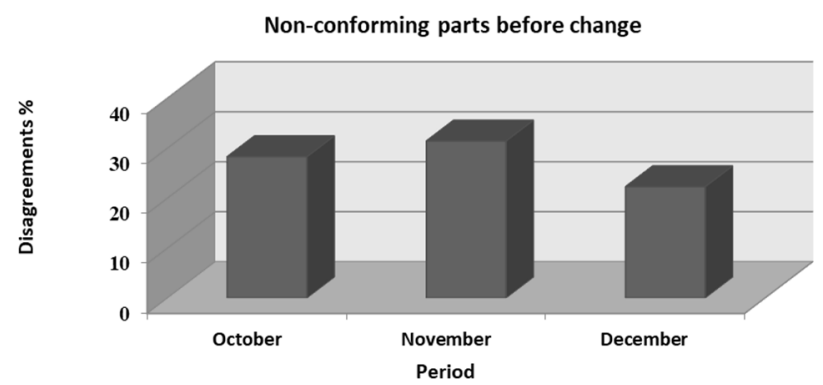

Fig. 1 Non-conforming parts before change

The development of the occurrence of non-conforming parts showed their high values in the range from $22.3 \%$ to $31.4 \%$, which subsequently caused high costs of poor quality. In addition to the basic information provided in the project charter, an important figure was the reduction of non-conforming furniture parts by $10 \%$, which was a priority of the Six Sigma implementation project.

The stage Measure and Analyse:

The measurement of the characteristics of the critical process, which was the application of glue in $\mathrm{g} / \mathrm{m}^{2}$ to the side surfaces of furniture parts and the use of the measurement plan for the technological conditions of the process, formed the basic platform of the measurement phase. Primary data were used to calculate the capability coefficients $C_{p}$ and $C_{p k}$. A comparison of the values of competence indices in furniture manufacturing processes is given in Table 2.

Table 2

Comparison of the values of the capability indices $C_{p}$ and $C_{p k}$ before and after the application of corrective measures

\begin{tabular}{lcc}
\hline \multirow{2}{*}{ Furniture production processes } & \multicolumn{2}{c}{$\begin{array}{c}\text { Values of capability } \\
\text { indices before }\end{array}$} \\
& $\mathrm{C}_{\mathrm{p}}$ & $\mathrm{C}_{\mathrm{pk}}$ \\
\hline Formatting & 1.30 & 0.93 \\
Pressing & 1.42 & 1.15 \\
Bonding of side surfaces & $\mathbf{1 . 1 7}$ & $\mathbf{1 . 1 1}$ \\
Grinding & 1.40 & 0.61 \\
Drilling holes & 1.42 & 1.20 \\
Mounting & 1.36 & 0.57 \\
\hline
\end{tabular}


From the Table 2 of comparison of capability coefficients, the lowest value is shown by the process of bonding the side surfaces.

Decomposition of the causes of disagreements of the first and second degree - Ishikawa diagram, using brainstorming and Pareto diagram to clarify the main causes of disagreements were selected methods in the Analysis phase. The causes of disagreements in the critical process are shown in absolute and cumulative terms in the Pareto diagram in Fig. 2.

How we can see from the Fig. 2 the low ability of the critical process is mainly caused by incorrect setting of the machinery, specifically the application of glue.

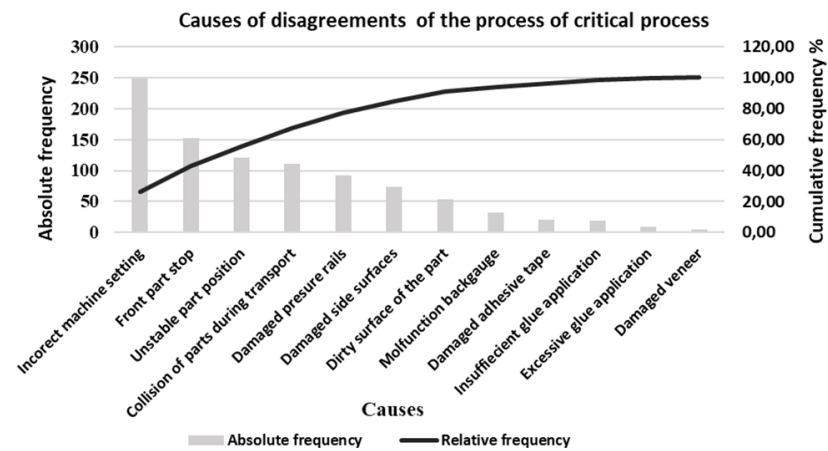

Fig. 2 Pareto diagram of causes disagreements of the critical process

In the stage of Improve it were process reaction plan, control diagrams, graphical methods of descriptive statistics, histogram, and correction simulation as can be seen in Fig. 3.

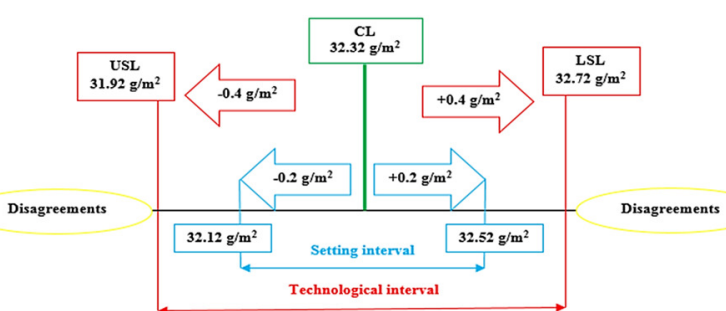

Fig. 3 Correction simulation of setting and technological interval

The correction simulation clearly shows the technological and setting intervals for the operation of the device for bonding the side surfaces of furniture parts. Corrective supplemented by the duty of the operator, is another method that was used in solving problems with setting up the device and is called the reaction plan. In the improvement phase, to the problem solving escalation diagram was also used, in which the process of informing, solving and deciding on problems arising according to individual levels of management and responsibility is graphically displayed.

In the stage of Control it were histogram, and $C_{p}$ and $C_{p k}$ capability indices a suitable tool for comparing the capability of furniture production processes in the implementation of the Six Sigma. The values of the indices $C_{p}$ and $\mathrm{C}_{\mathrm{pk}}$ after the implementation of corrective measures are given in Table 3.
Table 3

Comparison of the values of the capability indices $C_{p}$ and $C_{p k}$ before and after the application of corrective measures

\begin{tabular}{lcccc}
\hline $\begin{array}{c}\text { Furniture production } \\
\text { processes }\end{array}$ & \multicolumn{2}{c}{$\begin{array}{c}\text { Values indices } \\
\text { before }\end{array}$} & \multicolumn{3}{c}{$\begin{array}{c}\text { Values indices } \\
\text { after }\end{array}$} \\
\hline Processes & $\mathbf{C}_{\mathbf{p}}$ & $\mathbf{C}_{\mathbf{p k}}$ & $\mathbf{C}_{\mathbf{p}}$ & $\mathbf{C}_{\mathbf{p k}}$ \\
Formatting & 1.30 & 0.93 & 2.51 & 2.29 \\
Pressing & 1.42 & 1.15 & 2.81 & 2.80 \\
Bonding of side surfaces & 1.17 & 1.11 & 2.33 & 2.28 \\
Grinding & 1.40 & 0.61 & 2.77 & 1.97 \\
Drilling holes & 1.42 & 1.20 & 2.34 & 1.88 \\
Mounting & 1.36 & 0.57 & 2.26 & 1.87 \\
\hline
\end{tabular}

A positive development in the capability (Fig. 4) also occurred in the critical process, in which the value of the indices $C_{p}$ increased by 1.16 and $C_{p k}$ by 1.17 .

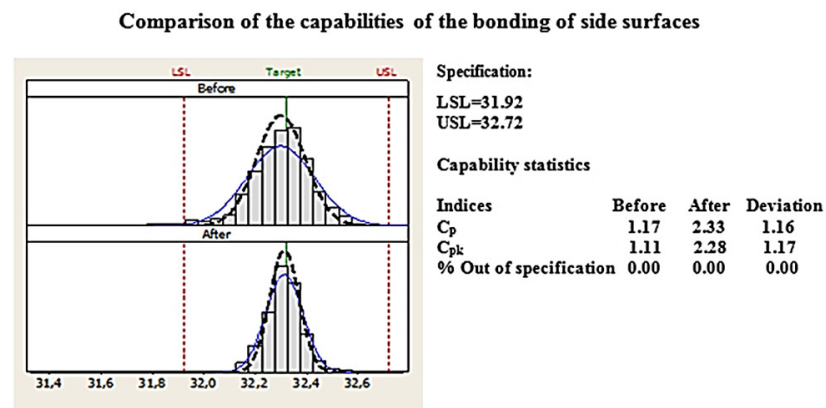

Fig. 4 Comparison of critical process capability indices

Favourable results after the application of corrective measures were also recorded for the values of DPMO, efficiency and sigma levels, which can be seen in Table 4 with an overview of the original and current values of the critical process.

Table 4

Comparison of DPMO values, efficiency and sigma levels of the critical process

\begin{tabular}{lccc}
\hline \multicolumn{1}{c}{ State } & DPMO & Efficiency \% & Sigma \\
\hline $\begin{array}{l}\text { Before the } \\
\text { change }\end{array}$ & 139389 & 86.06 & 2.58 \\
$\begin{array}{l}\text { After the } \\
\text { change }\end{array}$ & 47663 & 95.54 & 3.17 \\
\begin{tabular}{l} 
Difference \\
\hline
\end{tabular} & -91726 & +9.48 & +0.59 \\
\hline
\end{tabular}

Positive developments can be seen in all categories of critical process assessment, such as the DPMO value, which decreased by 91,726 , the efficiency level value increased by $9.48 \%$ and the sigma value increased by 0.59 . Based on the above analysis, we can state that the application of corrective measures met all the goals that were set at the beginning of the project to improve the performance and quality, specifically in the critical process.

The basic data for the economic assessment of the success of the selected procedures were the number of non-conforming products measured during the period of 3 months before and after the implementation of the proposed solutions and their mutual comparison. Percentage expression of the occurrence of non-conforming parts in bonding of side surfaces before and after the application of corrective measures for a period of 3 months are given in Fig. 5. 


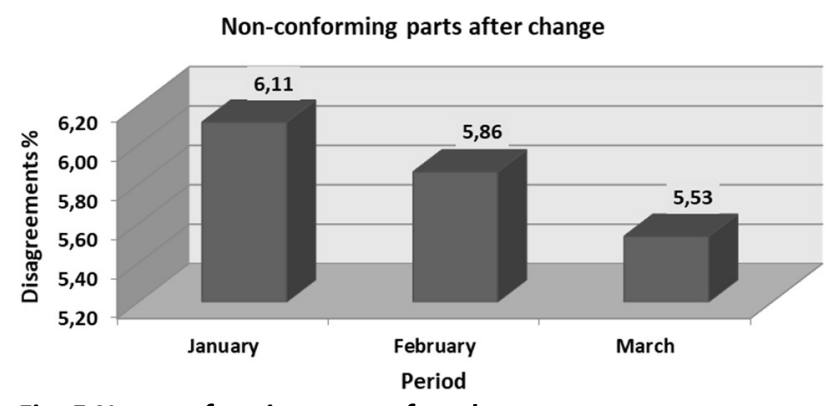

Fig. 5 Non-conforming parts after change

As we can see in Fig. 5, the percentages of non-compliant products in the process of bonding the side surfaces decreased, thus meeting the defined goal of reducing non-compliant products below $10 \%$.

In addition to data on non-conforming products in the critical process for a period of three months, specific furniture prices provided by the manufacturer were used in the economic evaluation of the savings achieved after the application of Six Sigma concepts and the application of corrective measures within this concept. Economic evaluation of the process of bonding the side surfaces of furniture parts is given in Table 5 .

Table 5

Economic benefits of six sigma implementation in a critical process

\begin{tabular}{lccc}
\hline \multicolumn{1}{c}{ State } & $\begin{array}{c}\text { Number of defective } \\
\text { parts pcs }\end{array}$ & $\begin{array}{c}\text { Price } \\
€ / \text { pcs }\end{array}$ & $\begin{array}{c}\text { Total } \\
\text { amount } €\end{array}$ \\
\hline Before the change & 483.00 & 12.50 & 6037.50 \\
After the change & 103.00 & 12.50 & 1287.50 \\
Difference & -380.00 & & 4750.00 \\
\hline
\end{tabular}

As we can see in Table 5 there was a decrease in non-compliant parts from 483 to 103 pieces, which represents a decrease of $27.33 \%$ of the total value of non-compliant products to the level of $5.83 \%$, thus achieving the set goals defined in the initial phase of the project.

We stated that after the implementation of the proposed solutions to improve the quality according to the Six Sigma methodology and the use methods according to the DMAIC steps, the costs were reduced by $78.67 \%$.

A positive result of the changes was an increase in the capability of furniture manufacturing processes and a reduction in the number of non-conforming parts, especially the critical process, where by adhering to all set process parameters, consistent and correct selection of concepts, methods and quality improvement tools can keep failure below $6 \%$.

\section{CONCLUSION}

The results of this article document that even today it is possible to achieve a significant improvement in quality and increase the efficiency of processes in the company with the help of correctly designed methods and procedures, with the use of consistently formulated goals and with an active approach of the whole team. This study focused on this area using the Six Sigma methodology within the DMAIC steps with an emphasis on the competence of furniture production processes, specifically the critical process of bonding the side surfaces of furniture parts.
Through Six Sigma and DMAIC steps in the furniture company, an improvement was achieved in all compared $C_{p}$ and $C_{p k}$ capability indicators, DPMO, efficiency level and sigma level values. The overall significant cost savings for low-quality furniture components, as well as specific recommendations for maintaining the achieved favourable state of process values, are helpful in illustrating the positive results of research evaluating and measuring process capability and performance not only in furniture companies.

\section{ACKNOWLEDGEMENTS}

This paper is the partial result of the projects No. 005TU Z-4/2020 under KEGA agency, Slovakia.

\section{REFERENCES}

[1] G. Anand, J.V. Gray. Strategy and organisation research in operations management, Journal of Operations Management, Vol. 53/56, 2017, pp. 1-8.

[2] R. Andersson, H. Eriksson, H. Torstensson. Similarities and differences between TQM, Six Sigma and Lea. The TQM Magazine, Vol. 18 No. 3, 2006, pp. 282-296.

[3] P. Gejdoš. Building and certification of quality management systems in theory and practice. Zvolen: TU Zvolen 2014.

[4] E.V. Gijo, J. Scaria, J. Antony. Application of six sigma methodology to reduce defects of a grinding process. Quality and Reliability Engineering International, Vol. 27 No. 8, 2011, pp. 1221-1234.

[5] G. Gong, J.C. Chen, G. Guo. Enhancing tensile strength of injection moulded fibre reinforced composites using the taguchi-based Six Sigma approach. International Journal of Advanced Manufacturing Technology 91 (9-12), 2017, pp. 3385-3393.

[6] C. Heavey, E. Murphy. Integrating the balanced scorecard with Six Sigma. The TQM Journal, Vol. 24 No. 2, 2012, pp. 108-122.

[7] S.S. Chakravorty, A.D. Shah. Lean Six Sigma (LSS): an implementation experience, European Journal of Industrial Engineering, Vol. 6 No. 1, 2012, pp. 118-137.

[8] P. Jirasukprasert, J. Arturo Garza-Reyes, V. Kumar, K. Lim. A Six Sigma and DMAIC application for the reduction of defects in a rubber gloves manufacturing process. International Journal of Lean Six Sigma, Vol. 5 No. 1, 2014, pp. 221.

[9] J. Kokkranikal, J. Antony, H. Kosgi, E. Losekoot. Barriers and challenges in the application of Six Sigma in the hospitality industry: some observations and findings. International Journal of Productivity and Performance Management, Vol. 62 No. 3, 2013, pp. 317-322.

[10] K. Linderman, R.G. Schroeder, A.S. Choo. Six Sigma: the role of goals in improvement teams. Journal of Operations Management, Vol. 24 No. 2, 2006, pp. 779-790.

[11] P.M. Madhani. Six Sigma Deployment in Sales and Marketing: Enhancing Competitive Advantages. IUP J. Bus. Strategy, 2017, pp. 40-63.

[12] W.J. Miller, R.J. Duesing, C.M. Lowery, A.T. Sumner. The quality movement from six perspectives. The TQM Journal, Vol. 30 No. 3, 2018, pp. 182-196.

[13] P.S. Pande, P.R Neumann, R.R. Cavanagh. We are introducing the Six Sigma method, TwinsCom, Brno, 2002, p. 416

[14] M.P.J Pepper, T.A. Spedding. The evolution of Lean Six Sigma, International Journal of Quality \& Reliability Management, Vol. 27 No. 2, 2010, pp. 138-155. 
[15] Qureshi, M.I., Janjua, S.Y., Zaman, K., Lodhi, M.S. and Tariq, Y.B. (2014), "Internationalization of higher education institutions: implementation of DMAIC cycle", Scientometrics, Vol. 98 No. 3, pp. 2295-2310.

[16] S. Ray, P. Das. Improving machining process capability by using Six Sigma, International Journal for Quality Research, 5(2), 2011, pp. 109-121.

[17] S. Shaaban, A.S. Darwish. Production Systems: Successful applications and new challenges part one-Lean, Six Sigma, and inventory, JIT and TOC, Prod. Plan. Control, 2016, pp. 539-540.

[18] L'. Simanová. Specific proposal of the application and implementation Six Sigma in selected processes of the furniture manufacturing, Procedia - economics and finance. Vol. 34, 2015, pp. 268-275.

[19] L'. Simanová, P. Gejdoš. Application of selected methods and approaches for improvement of processes and their use in practice in companies of wood processing industry in Slovakia, Management Systems in Production Engineering. Vol. 27, issue 3, 2019, pp. 162-165.

\section{L'ubica Simanová}

ORCID ID: 0000-0003-0374-2926

Technical University in Zvolen

Faculty of Wood Sciences and Technology

Department of Economics, Management and Business

T. G. Masaryk 2117/24, 96001 Zvolen, Slovak Republic e-mail: simanova@tuzvo.sk

\section{Pavol Gejdoš}

ORCID ID: 0000-0002-4665-9762

Technical University in Zvolen

Faculty of Wood Sciences and Technology

Department of Economics, Management and Business T. G. Masaryk 2117/24, 96001 Zvolen, Slovak Republic e-mail: gejdosp@tuzvo.sk
[20] A. Soti, R. Shankar, O.P. Kaushal, Modelling the enablers of Six Sigma using interpreting structural modelling, Journal of Modelling in Management, Vol. 5 No. 2, 2010, pp. 124141.

[21] Schroeder, R.G., Linderman, K., Liedtke, C. and Choo, A.S. (2008), "Six Sigma: definition and underlying theory", Journal of Operations Management, Vol. 26 No. 4, pp. 536-554

[22] Stat Soft. Inc. (2013). STATISTICA, version 12. www.statsoft.com.

[23] C.H. Wang, M.L. Tseng, K.H. Tan, K.T. Yu. Application of a mathematical programming model to solve the confidence interval. International Journal of Information and Management Sciences 28 (1), 2017, pp. 11-23.

[24] W. Yerriswamy, D.R. Swamy, P. Nagesh. The process capability analysis - a tool for process performance measures and metrics - a case study. International Journal for Quality Research, 8(3), 2014, pp. 399-416.

[25] X. Zu, L.D. Fredendall, T.J. Douglas. The evolving theory of quality management: the role of Six Sigma, Journal of Operations Management, Vol. 26 No. 5, 2008, pp. 630-650. 